\title{
Mapas Conceituais como estratégia de estudo em tempos de pandemia: uma experiência com estudantes de uma escola pública?
}

\author{
Jair Pedro da Fé Neto \\ Edmilson Minoru Torisu
}

\begin{abstract}
Resumo: 0 objetivo deste estudo foi investigar as percepções de estudantes sobre 0 uso dos Mapas Conceituais como estratégia de estudo para o ENEM, em tempos de pandemia. Os sujeitos foram estudantes do terceiro ano do Ensino Médio de uma escola pública de Minas Gerais. A teoria subjacente ao estudo é a Teoria da Aprendizagem Significativa e a coleta de dados foi realizada por meio dos registros dos estudantes, formulário Google Forms, whatsapp e em roda de conversa pela plataforma Google Meet. Os resultados revelaram que, para os estudantes: os Mapas servem para estruturar um resumo da matéria; ajudam a memorizar o conteúdo; contribuem para a economia de tempo de estudo; possuem uma estrutura que ajuda aqueles que têm mais dificuldade para aprender os conteúdos e, ajuda a organizar o estudo.
\end{abstract}

Palavras-chave: Aprendizagem Significativa. Mapas conceituais. Medidas de Tendência Central. Educação Matemática.

\section{Conceptual Maps as study strategy in pandemic times: an experience with students from a public school?}

\begin{abstract}
The aim of this study was to investigate the perceptions of students about the use of Concept Maps as a study strategy for ENEM, in times of pandemic. The subjects were students of the third year of high school at a public school in Minas Gerais. The theory underlying the study is the Theory of Meaningful Learning and data collection was carried out through student records, Google Forms, whatsapp and in a conversation round the Google Meet platform. The results revealed that, for the students: the Maps serve

Jair Pedro da Fé Neto Mestrando em Educação Matemática

to structure a summary of the subject; help to memorize the content; contribute to the saving of study time; they have a structure that helps those who have more difficulty in learning the contents and helps to organize the study.
\end{abstract} pela Universidade Federal de Ouro Preto, Ouro Preto, Minas Gerais, Brasil.

(D) http://orcid.org/0000-0003-0901-4882 jair.pbh@gmail.com

Edmilson Minoru Torisu Doutor em Educação pela Universidade Federal de Minas Gerais. Professor do Departamento de Educação Matemática e do Programa de Pós-Graduação em Educação Matemática, ambos da Universidade Federal de Ouro Preto Ouro Preto, Minas Gerais, Brasil. iD https://orcid.org/0000-0001-9395277X etorisu@gmail.com

Recebido em 14/10/2020

Aceito em 01/12/2020

Publicado em 21/12/2020
Keywords: Meaningful Learning. Concept maps. Central Trend Measures. Mathematical Education.

\section{Mapas Conceptuales como estrategia de estudio en tiempos de pandemia: ¿una experiencia con alumnos de un colegio público?}

Resumen: El objetivo de este estudio fue investigar las percepciones de los estudiantes sobre el uso de Mapas Conceptuales como estrategia de estudio para ENEM, en tiempos de pandemia. Los sujetos eran estudiantes de tercer año de secundaria en una escuela pública de Minas Gerais. La teoría que sustenta el estudio es la Teoría del Aprendizaje Significativo y la recolección de datos se llevó a cabo a través de registros de estudiantes, formularios de google, whatsapp y en una conversación en la plataforma de encuentro de google. Los resultados revelaron que, para los estudiantes: los Mapas sirven para estructurar un resumen de la asignatura; ayudar a memorizar el contenido; contribuir al ahorro de tiempo de estudio; tienen una estructura que ayuda a quienes tienen más dificultades para aprender los contenidos y ayuda a organizar el estudio.

Palabras clave: Aprendizaje significativo. Mapas conceptuales. Medidas de tendencia central. Educación Matemática. 


\section{Introdução}

O Brasil vem enfrentando, ao longo de sua história, vários problemas no âmbito da Educação. Dentre eles, de acordo com Prandi et al. (2015), podemos destacar problemas relacionados aos mecanismos de ensino e aprendizagem, à remuneração dos professores e à capacitação desses profissionais, ao déficit material obsoleto disponivel para uso nas aulas e aos desacertos de gestão de ensino e planejamento. Além desses, Franco et al. (2006) apontam problemas relacionados às más condições socioeconômicas de muitas famílias de estudantes, ao parco investimento do governo na área educacional e à qualidade da formação do professor.

Sendo assim, propostas que visem a mudanças nesse cenário são bem-vindas e necessárias. Particularmente, podemos pensar em propostas que contribuam para uma prática do professor em sala de aula que seja mais atrativa aos estudantes. Como uma possibilidade nessa direção, as metodologias ativas (MA) surgem como bastante promissoras no processo de transformação do ensino tradicional. Ainda sobre as contribuições das MA para o ensino, Morán (2015, p. 18) afirma que "as metodologias ativas são pontos de partida para avançar para processos mais avançados de reflexão, de integração cognitiva, de generalização, de reelaboração de novas práticas".

Em complemento às ideias de Morán (2015), Diesel, Baldez e Martins (2017) consideram que as MA inserem os estudantes no centro do processo de ensino e aprendizagem, indo de encontro ao paradigma que reserva a eles o papel de mero expectador e receptor passivo daquilo que ocorre em sala de aula.

O presente estudo, de caráter qualitativo, teve por finalidade investigar percepções de estudantes do terceiro ano do Ensino Médio acerca do uso dos Mapas Conceituais como estratégia de estudo para 0 ENEM, em tempos de pandemia. Os estudos ocorreram em aulas de Matemática de uma escola pública do Estado de Minas Gerais.

Vale ressaltar que o contexto no qual se insere o estudo é o da pandemia do Coronavírus, mundialmente conhecido por COVID-191. Nesse cenário, caracterizado pela emergência de novos desafios em todas as áreas, particularmente em educação, torna-se necessário refletir sobre como os professores podem utilizar esse tempo de estudos remotos, de forma a garantir, aos estudantes, aprendizagens que minimizem os impactos da ausência de aulas presenciais, bem como da possível fragilidade causada pelo não contato direto com o professor, característico do ensino presencial.

Em diversos países, os estudantes estão participando de experiências com aulas remotas, dentre os quais destacamos, Áustria, República Tcheca, Grécia e Itália. A depender da forma como estas

\footnotetext{
${ }^{1}$ A COVID-19 é uma doença causada pelo coronavírus, denominado SARS-CoV-2, que apresenta um espectro clínico variando de infecções assintomáticas a quadros graves. De acordo com a Organização Mundial de Saúde, a maioria (cerca de $80 \%$ ) dos pacientes com COVID-19 podem ser assintomáticos ou oligossintomáticos (poucos sintomas), e aproximadamente $20 \%$ dos casos detectados requer atendimento hospitalar por apresentarem dificuldade respiratória, dos quais aproximadamente $5 \%$ podem necessitar de suporte ventilatório. Fonte: www.coronavirus.saude.gov.br
} 
experiências são conduzidas, o saldo pode ser positivo e inaugurar novos formatos de ensino que vieram para ficar. Contudo, se as experiências apenas trocam a lousa pela tela do computador, sem apresentar algo que instigue a curiosidade dos estudantes, o resultado pode ser a apatia e o desinteresse.

No Brasil, um dos maiores desafios que se apresenta aos professores é encontrar caminhos profícuos de modo que o ensino remoto emergencial contribua, da melhor forma possível, para a aprendizagem dos estudantes, inclusive preparando-os para o Exame Nacional do Ensino Médio (ENEM). No caso especifico do ENEM, por meio do qual os estudantes concorrem a vagas no Ensino Superior, o desafio parece ainda maior por que pode gerar anseios e temores.

Em um contexto de pandemia, esses sentimentos afloram nos estudantes de forma mais intensa, comprometendo a sua saúde física e mental. De acordo com Maia e Dias (2020 apud Dias; Pinto, 2020, p. 2), fatores como

A duração prolongada do confinamento, a falta de contato pessoal com os colegas de classe, o medo de ser infectado, a falta de espaço em casa - tornam o estudante menos ativo fisicamente do que se estivesse na escola, e a falta de merenda para os alunos menos privilegiados são fatores de estresse que atingem a saúde mental de boa parte dos estudantes da Educação Básica e das suas famílias.

Ainda em relação à saúde mental, Cipriano e Almeida (2020) destacam que, além dos estudantes, os professores também são afetados pela rotina do isolamento social e privação de um contato humano presencial, originando problemas psicológicos como resultado da elevada carga emocional, física e de papéis sociais, "facilitando o desencadeamento, agravamento ou recidiva de transtornos mentais ou doenças físicas" (CIPRIANO; ALMEIDA, 2020, p. 4).

O ENEM ocorre anualmente e as inscrições são, majoritariamente, de estudantes do terceiro ano do Ensino Médio, na tentativa de ingressar em universidades públicas e privadas por intermédio de bolsas de estudos. Em 2020, em razão da pandemia, o ENEM foi adiado para o início de 2021 e isso pode ter aumentado ainda mais a instabilidade emocional dos discentes, já angustiados com as incertezas em relação ao futuro profissional.

Diante de todo o exposto, este texto investiga e analisa uma proposta para o estudo de medidas de tendência central utilizando Mapas Conceituais, considerados como uma MA. Essa proposta foi implementada durante a pandemia em aulas remotas.

Organizamos este artigo em sete seções. A segunda e terceira seções apresentam o referencial teórico. As seções 4 e 5 foram destinadas para a proposta metodológica e os caminhos percorridos na pesquisa. A análise e reflexão dos dados produzidos compõem a sexta seção. Na sétima e última seção traçamos as considerações finais. 


\title{
2 Mapas Conceituais, o que são?
}

Uma das grandes dificuldades enfrentadas pelos estudantes no processo de ensino e aprendizagem está ligada à associação dos conteúdos estudados com o que é vivido no cotidiano. De modo geral, há dificuldades em estabelecer conexões entre os conteúdos e conceitos e isso ocorre porque, ainda que esses últimos sejam conhecidos dos estudantes e utilizados com frequência, muitos não estão devidamente estruturados e/ou internalizados (JÚNIOR, 2013). Em outras palavras, isso significa que, embora os estudantes saibam verbalizar os conceitos, muitos são os obstáculos encontrados por eles para explicarem com clareza o seu significado, além de não conseguirem estabelecer uma relação com outros conceitos, bem como utilizá-los em situações factuais.

Para algumas pessoas, 0 ato de conceituar relaciona-se apenas à verbalização de um determinado termo ou objeto, provocando uma compreensão simplista da aprendizagem e dando a impressão de que não há diferença entre expressão verbal e compreensão (JÚNIOR, 2013). Então,

\begin{abstract}
A definição se refere à caracterização do conceito, sendo este mais do que a verbalização das características de um termo ou objeto, vinculando-se a uma atividade psicológica complexa que consiste em abstrair as características essenciais de determinado termo ou objeto, estabelecendo discriminações, relações e representações para chegar a uma generalização. Nas generalizações, os conceitos possibilitam que as palavras representem classes inteiras de objetos, qualidades ou acontecimentos (JÚNIOR, 2013, p. 442).
\end{abstract}

Nesse direcionamento, os conceitos como representações por signos linguísticos, são elaborados e efetivados dentro do próprio indivíduo e, ao estabelecerem ordem para as ocorrências do mundo real em categorias, modelam suas percepções sobre o mundo. Para Júnior (2013),

\begin{abstract}
Em cada momento da vida, o indivíduo dispõe de certa espécie de rede de conceitos interligados por relações de semelhança, contiguidade e subordinação, representando seu conhecimento acumulado sobre as coisas e o filtro através do qual será capaz de interpretar os fatos, eventos e situações com que se depara no mundo objetivo (JÚNIOR, 2013, p. 442).
\end{abstract}

Portanto, como um aspecto do funcionamento cognitivo, o processo de construção de conceitos é uma das abordagens mais importantes do ensino e as relações coerentes entre eles darão sinal de sua real compreensão por parte do indivíduo.

Uma possibilidade para que os estudantes tenham oportunidades de estabelecer relações entre conceitos aprendidos, criando um todo coerente, é a utilização de Mapas Conceituais. De acordo com Grillo et al. (2008),

Mapas conceituais são representações gráficas de conjuntos de conceitos organizados sob a forma de diagramas, que indicam relação entre esses conceitos. Embora aparentemente simples e até mesmo confundidos com esquemas ou organogramas, os mapas têm como especificidade tornar evidentes os significados 
atribuídos a conceitos e esclarecer as relações existentes entre os mesmos, em determinada área de conhecimento, de um curso, de uma disciplina, de um artigo, de uma palestra, entre outras (GRILLO et al., 2008, p. 145).

Os Mapas Conceituais, de acordo com as autoras, são sempre representações pessoais e, por conseguinte, não são autoexplicativos, sendo necessário que o autor do Mapa explique os sentidos e os significados que foram atribuídos aos conceitos e às suas relações. A nosso ver, se por um lado isso parece um fator limitador, pois seria difícil que o Mapa fosse utilizado por outra pessoa para melhor compreender um tema, por outro, exige que o autor tenha o domínio completo das relações entre os conceitos utilizados, com pena de não realizar uma boa explicação que seja a ele solicitada. Outra consequência do fato de os Mapas serem individuais é que não existe um único Mapa Conceitual considerado correto, possibilitando que diversos Mapas Conceituais oriundos de uma mesma fonte de conhecimento sejam construídos (GRILLO et al., 2008).

Os Mapas Conceituais são dispostos, geralmente, de modo hierárquico, de forma que os conceitos considerados gerais e ou/abrangentes estejam no topo, e os conceitos tidos como específicos e/ou secundários distribuem-se em direção à base assumindo, então, uma configuração piramidal não obrigatória. Contudo, os Mapas Conceituais não têm uma fórmica preestabelecida, pois depende da estrutura conceitual que ele representa (GRILLO et al., 2008). De acordo com Moreira (1997),

O importante é que o mapa seja um instrumento capaz de evidenciar significados
atribuídos a conceitos e relações entre conceitos no contexto de um corpo de
conhecimentos, de uma disciplina, de uma matéria de ensino. Por exemplo, se o
indivíduo que faz um mapa, seja ele, por exemplo, professor ou aluno, une dois
conceitos, através de uma linha, ele deve ser capaz de explicar o significado da relação
que vê entre esses conceitos. [...] uma ou duas palavras-chave escritas sobre essa
linha podem ser suficientes para explicitar a natureza dessa relação. Os dois conceitos
mais as palavras-chave formam uma proposição e esta evidencia o significado da
relação conceitual (MOREIRA, 1997, p. 1-2). O quadro 1 apresenta ideias que podem ser utilizadas para a construção de Mapas Conceituais. 
Quadro 1 - Ideias para a construção de um Mapa Conceitual

Os Mapas Conceituais devem reunir um número pequeno de conceitos e ideias de forma que o aluno possa
realmente expressar o que compreendeu de determinado conteúdo;
Isolar conceitos e palavras de ligação, entendendo que estas categorias de palavras vão desempenhar
diferentes funções;
Hierarquizar os conceitos, colocando na parte superior os mais gerais (inclusivos) e na parte inferior os mais
específicos (menos inclusivos);
Devem ser montados várias vezes, pois o primeiro que se constrói quase sempre tem algum defeito e após
uma releitura sempre é possível fazer ajustes que tornem mais claros ou que permitem melhorar as ligações;
O Mapa Conceitual deve ser acessível ao entendimento de outro indivíduo com o mesmo nível de
conhecimento, a fim de observar os aspectos visuais e os conceitos formados.

Fonte: Elaborado pelos autores. Adaptado Lima; Lima; Melo (2016 apud ONTORIA et al., 2004, p.3).

A figura 1 apresenta um exemplo deles, onde podemos observar várias de suas características.

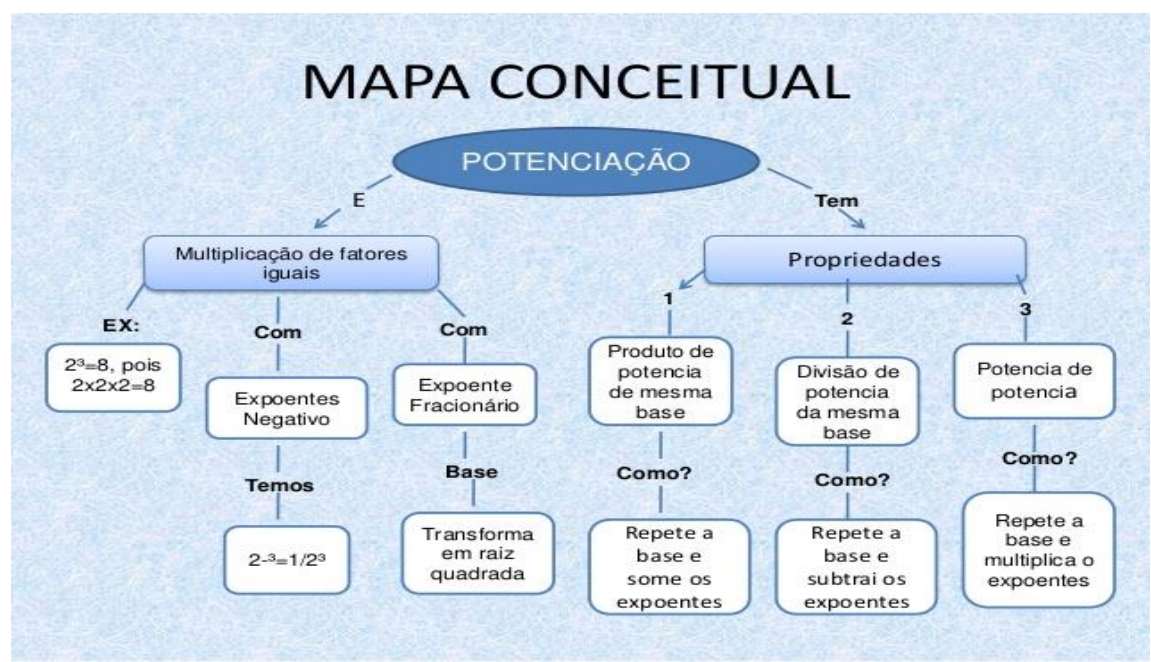

Figura 1: Mapa Conceitual potenciação (AZEVEDO, 2015, p. 9).

O exemplo acima apresenta um Mapa bidimensional, que explicita relações de conceitos nas dimensões horizontal e vertical, por isso, de mais fácil compreensão que os unidimensionais, que restringem-se a uma lista de conceitos em uma organização vertical e, portanto, mais pobres na representação do significado (GRILLO et al., 2008).

Moreira e Buchweitz (1993 apud Moreira, 1997), consideram que o Mapa Conceitual é uma técnica bastante flexível, podendo ser utilizado como instrumento de análise do currículo, técnica didática, recurso de aprendizagem, meio de avaliação. Como recurso para aprendizagem em sala de aula, Moreira (1997) sugere que seja utilizado quando os estudantes já estiverem familiarizados com 0 assunto, para que a aprendizagem seja potencialmente significativa. Para este autor, ao utilizarem este recurso para analisar 
artigos, livros e outros materiais educativos, os estudantes estarão usando o mapeamento conceitual como um recurso de aprendizagem.

\section{A teoria por trás dos Mapas Conceituais}

O fundamento teórico subjacente aos Mapas Conceituais é a (TAS) Teoria da Aprendizagem Significativa (GRILLO et al., 2008) de David Ausubel, embora esse autor não faça menção a eles em suas obras. Os Mapas Conceituais são uma técnica desenvolvida por John Novak, que também trabalhou com Ausubel nos estudos sobre a aprendizagem (GRILLO et al., 2008).

$\mathrm{Na}$ escola, uma aprendizagem é dita significativa quando um novo conceito adquire significados para o estudante, ao apoiar-se (ou ancorar-se) em outros conceitos com determinado grau de clareza e estabilidade, existentes em sua estrutura cognitiva. Esses conceitos preexistentes que servem de ancoradouro para os novos conceitos são denominados subsunçores. Contudo, os subsunçores não são estáticos. Ao darem apoio aos novos conceitos, ambos se modificam, formando um conjunto diferenciado, estável, podendo vir a ser um novo subsunçor, ao qual novos conceitos se ligarão. Dessa forma, a estrutura cognitiva do estudante está sempre se reestruturando, em um processo dinâmico (MOREIRA, 1997).

Contudo, é importante ressaltar que a internalização de novos conceitos, da forma como descrita acima, nunca é algo literal e arbitrária porque no processo há um componente pessoal, idiossincrático, que é a significação. "Aprender significativamente implica atribuir significados e estes têm sempre componentes pessoais. Aprendizagem sem atribuição de significados pessoais, sem relação com o conhecimento preexistente, é mecânica, não significativa" (MOREIRA, 1997, p. 5).

Novak e Canãs (2010) apresentam três características da aprendizagem significativa para diferenciá-la da aprendizagem mecânica. De acordo com os autores, o aprendizado significativo requer as seguintes condições: 1 - o conhecimento a ser aprendido deve ser conceituado de forma clara e apresentado com linguagem e exemplos, de modo que o estudante possa relacioná-lo com seus conhecimentos anteriores; 2 - o estudante deve possuir conhecimentos anteriores relevantes; 3 - 0 estudante deve estar disposto e querer aprender significativamente.

Notamos que as condições 1 e 2 estão interrelacionadas. A terceira condição, relacionada ao desejo do estudante de aprender de modo significativo, não pode ser controlada pelo professor, mas este pode, ao longo de sua prática pedagógica, agir no sentido de contribuir para aumentar o interesse do estudante. Isso posto, como Mapas Conceituais podem possibilitar uma aprendizagem significativa?

De acordo com Novak e Canãs (2010), apoiados em Ausubel, Mapas Conceituais podem ajudar a cumprir a primeira condição citada acima,

[...] tanto por identificar conceitos amplos e gerais possuídos pelo aprendiz antes de ele aprender conceitos mais específicos, quanto por ajudar no sequenciamento de 
tarefas de aprendizagem através de conhecimentos progressivamente mais explícitos, que podem se basear em quadros de desenvolvimento conceitual (NOVAK; CANÃS, 2010, p. 11).

Em outras palavras, ao partir de conceitos mais gerais (subsunçores), presentes na estrutura cognitiva do estudante e localizados no topo da estrutura dos Mapas, o professor pode organizar suas ações de modo a ensinar (novos) conceitos, mais específicos (em posição hierárquica no sentido do topo para a base), que se liguem aos mais gerais, compondo um todo coerente e que pode ser logicamente compreendido pelo estudante. Os Mapas produzidos oferecerão um retrato de como cada um dos estudantes se apropriou das novas aprendizagens, ou seja, o processo de construção dos Mapas Conceituais possibilita a externalização do conhecimento por intermédio de uma representação visual que cada indivíduo elabora estruturada em conceitos, palavras de ligações e proposições.

\section{Mapas Conceituais como recurso para ensinar estatística nas aulas de Matemática: uma proposta}

$\mathrm{Na}$ introdução deste texto, trouxemos uma discussão sobre o uso de MA como uma possibilidade para promover mudanças no ensino tradicional (colocando o estudante no centro do processo de ensino e aprendizagem) e, ao mesmo tempo, como uma possibilidade para enfrentar, com a melhor qualidade possível, os desafios para ensinar em um cenário de pandemia. Conforme afirmado por Novak (2000), os Mapas Conceituais emergiram a partir da associação com a TAS de Ausubel.

A figura a seguir, apresenta um Mapa Conceitual que representa a relação entre o conceito principal que é "Metodologia Ativa" e os secundários que abarcam, entre outros, estudos de caso, estudos simulados, seminários e aprendizagem por projetos.

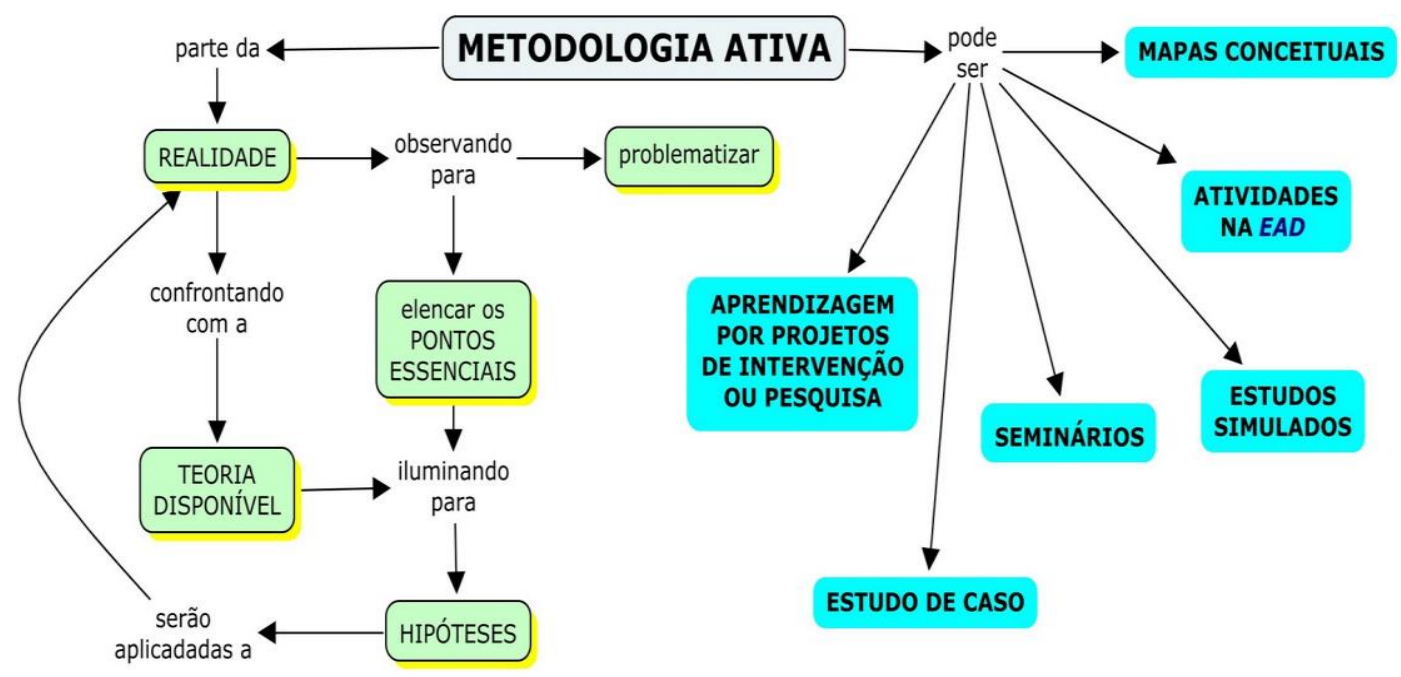

Figura 2: Mapa Conceitual da Metodologia Ativa (PIMENTEL, 2010, p. 5). 
$\mathrm{Na}$ figura 2, nota-se ao lado esquerdo a função das MA, que parte da realidade para ser confrontada com a teoria, problematizar e formular hipóteses. 0 ramo a direita do leitor, expõe algumas possibilidades de MA, entre as quais, engloba os Mapas Conceituais, que é o foco deste estudo. Acreditamos que os Mapas promovam um ensino em que o estudante protagoniza sua aprendizagem, como propõe uma MA.

Os Parâmetros Curriculares Nacionais (PCN) de Matemática, embora não utilizem os termos Mapa Conceitual e aprendizagem significativa, apresentam ideias muito próximas relativas a eles.

[...] a matemática tem um valor formativo, que ajuda a estruturar o pensamento e 0 raciocínio dedutivo, porém também desempenha um papel instrumental, pois é uma ferramenta que serve para a vida cotidiana e para muitas tarefas específicas em quase todas as atividades humanas. [...] mas também deve ser vista como ciência, nesse sentido 0 aluno deve perceber que as definições, demonstrações e encadeamento conceituais e lógicos têm a função de construir novos conceitos e estruturas a partir de outros e que servem para validar intuições e dar sentido às técnicas aplicadas (BRASIL, 1999, p. 40-41, grifo nosso).

Podemos analisar os "encadeamentos conceituais e lógicos" como algo próximo das relações entre conceitos contidas nos Mapas Conceituais e, "construir novos conceitos e estruturas a partir de outros" como algo próximo do que ocorre no processo de ancoragem, discutido na TAS, na qual um subsunçor serve de ancoradouro para um novo conceito.

O uso de Mapas Conceituais parece ser, então, uma proposta promissora para que os estudantes aprendam, de forma significativa, novos conceitos. Contudo, como nos alerta Júnior (2013), a aprendizagem só será efetiva, caso o professor esteja imbuído do desejo de proporcionar isso aos estudantes e estes desejem aprender.

As medidas de tendência central: moda, média e mediana, parte dos estudos de estatística, são comumente estudadas em aulas de Matemática e recorrentemente abordadas em questões do ENEM.

Preocupado com as limitações impostas pela pandemia, o primeiro autor deste artigo, professor da rede pública de ensino do estado de Minas Gerais, vislumbrou a possibilidade de ensinar estatística (Medidas de Tendência Central) por meio de Mapas Conceituais, como forma de preparação para o ENEM. Além da aprendizagem, propriamente dita, interessava-nos investigar e analisar as percepções dos estudantes acerca da proposta.

Para atingir a esse objetivo, alguns procedimentos foram adotados e serão descritos na próxima seção. 


\section{Caminhos da pesquisa}

Os sujeitos da pesquisa foram estudantes do terceiro ano do Ensino Médio de uma escola estadual, localizada na região metropolitana de Belo Horizonte, Minas Gerais. Muitos deles vieram de famílias de baixa renda e tiveram que trabalhar para ajudar os pais nas despesas domésticas. Mesmo diante de dificuldades financeiras (e outras), agravadas pela pandemia do Coronavírus, os estudantes acreditam em uma vida melhor, por meio da educação. O pesquisador, como já informamos, era o professor de Matemática da turma.

No momento do estudo, o governo mineiro havia adotado algumas medidas para mitigar os prejuízos aos estudantes da rede pública de ensino, em termos de aprendizagem. Teleaulas passaram a ser veiculadas pela Rede Minas de televisão e um material didático, composto por conteúdos teóricos e exercícios, denominado (PET) Plano de Estudo Tutorado², foi elaborado pela Secretaria de Educação como apoio às aulas virtuais. Além disso, o governo disponibilizou um aplicativo para download, por meio do qual os estudantes esclarecem dúvidas com os professores.

O professor de Matemática, que estava ensinando medidas de tendência central, idealizou uma proposta que pudesse ser implementada paralelamente às aulas pela televisão, utilizando outros recursos tecnológicos, como o aplicativo de mensagens whatsapp e a plataforma para reuniões virtuais Google Meet, para promover aprendizagens significativas em estatística, por meio de Mapas Conceituais. Acreditava-se que a proposta com Mapas pudesse auxiliar na sistematização dos conceitos das medidas de tendência central como forma de estudo para o ENEM.

Foram três as etapas que compuseram a proposta:

- $1^{\circ}$ etapa

A primeira etapa foi de organização. Enviamos um Plano de Atividades ao setor pedagógico da escola, contendo a apresentação da proposta, seus objetivos, a metodologia empregada, e os possíveis impactos na aprendizagem matemática dos alunos do $3^{\circ}$ ano do Ensino Médio. Ao grupo de whatsapp dos estudantes foram enviados dois vídeos curtos e interativos, com informações a respeito de Mapas Conceituais: definição, modo de confeccionar, aplicações e os seus benefícios na promoção de uma aprendizagem significativa.

\section{- $2^{\circ}$ etapa}

Na segunda etapa, os estudantes foram convidados a confeccionar Mapas Conceituais, tomando por base o conteúdo das medidas de tendência central, mais especificamente, moda, média aritmética simples, média aritmética ponderada e mediana. Esse conteúdo já havia sido estudado no PET volume 2. Portanto, a solicitação dos Mapas aos estudantes corrobora a sugestão de Moreira (1997), de que o uso

\footnotetext{
2 Disponivel em: https://estudeemcasa.educacao.mg.gov.br/
} 
de Mapas deve ocorrer, preferencialmente, depois que os estudantes estiverem mais familiarizados com o conteúdo. Dessa segunda etapa participaram seis estudantes, que deveriam enviar, ao whatsapp do professor, os Mapas confeccionados. O pequeno número de participantes está relacionado a alguns fatores, dos quais destacamos: falta de tempo provocada pelo trabalho fora de casa, falta de recursos, desestímulo diante de uma possível perda do ano letivo, como consequência da pandemia.

Aos que participaram, solicitamos o preenchimento de um formulário criado na plataforma Google Forms, composto por perguntas relacionadas ao uso de Mapas Conceituais, particularmente a sua utilidade para a aprendizagem das medidas de tendência central, levando em conta a preparação para o ENEM.

- $3^{\circ}$ etapa

A terceira etapa consistiu de uma roda de conversa virtual por meio da plataforma Google Meet, realizada com quatro dos seis participantes da etapa anterior. 0 objetivo era organizar uma conversa franca, sem grandes formalidades, para colher informações/reflexões dos estudantes, acerca do processo. O momento seria adequado, também, para o professor ressaltar a importância dessa MA no ensino, sua relevância na sistematização de conceitos e, principalmente, a sua utilização no preparo para o ENEM.

\section{Reflexões e análises da prática}

Nesta seção, apresentaremos os Mapas Conceituais (Figuras 3, 4, 5 e 6) apresentados por quatro estudantes, cujos nomes reais foram substituídos pelos nomes fictícios, Kelly, Amanda, Guto e Carla, por questões éticas. As análises também serão realizadas nesta seção.

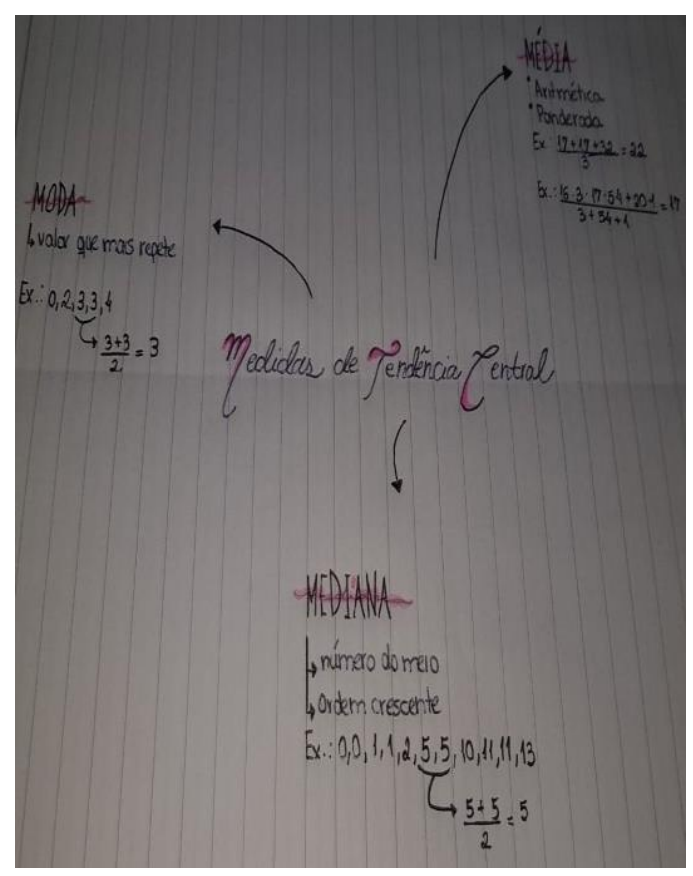

Figura 3: Mapa Conceitual da Kelly (dados da pesquisa, 2020). 


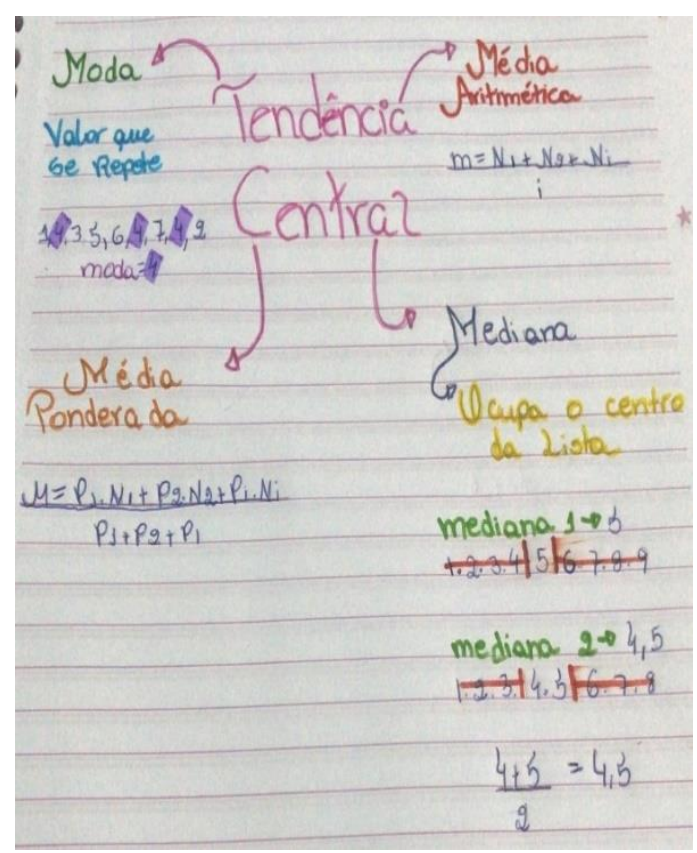

Figura 4: Mapa Conceitual da Amanda (dados da pesquisa, 2020).

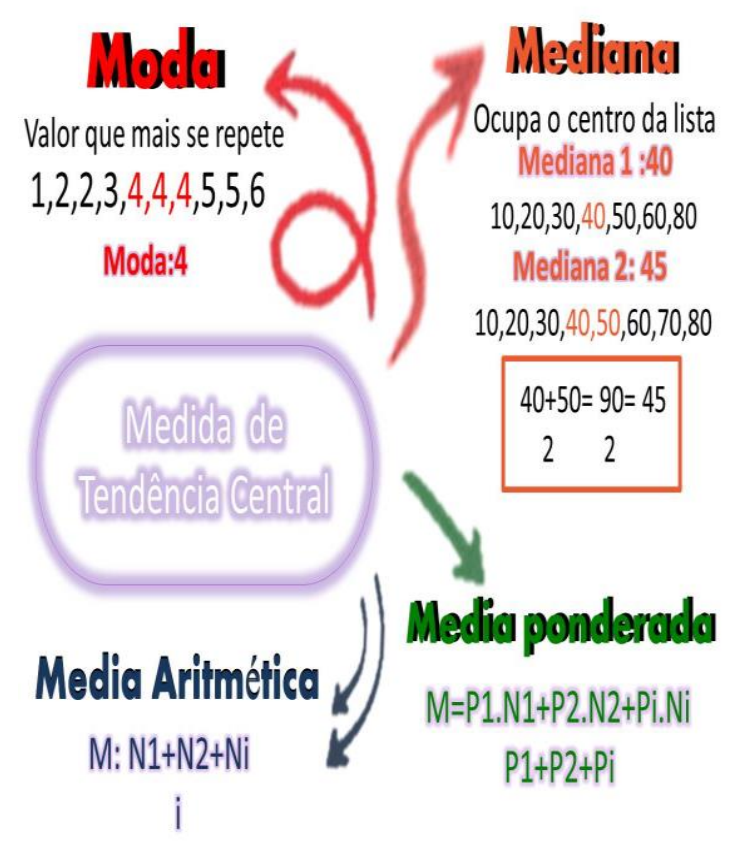

Figura 5: Mapa Conceitual do Guto (dados da pesquisa, 2020). 


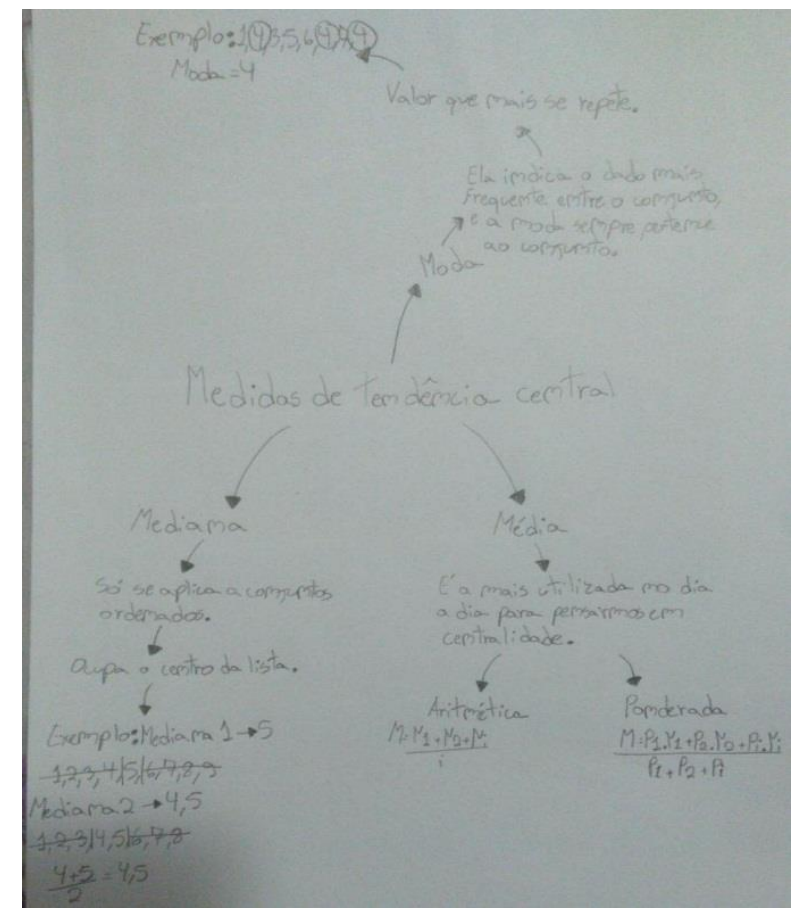

Figura 6: Mapa Conceitual da Carla (dados da pesquisa, 2020).

Nas figuras 3, 4, 5 e 6, podemos perceber que os alunos utilizaram o conceito Medida de Tendência Central como o termo geral, mais abrangente para, a partir dele, e utilizando setas orientandas, ramificar para conceitos mais específicos, assim como propõem os autores quando da construção de Mapas Conceituais. Dessa forma, os estudantes demonstraram suas formas particulares de estabelecer interrelações entre os conceitos apresentados, compondo um todo que, em suas perspectivas, pareciam coerentes e significativas.

Uma possibilidade de análise dos Mapas, à luz da TAS, é que o conceito de medidas de tendência central pode ter sido utilizado como subsunçor em um momento inicial. Os conceitos, moda, mediana e média, por serem tipos de medidas de tendência central, podem ter se ancorado nesse conceito para trazer significado aos estudantes. Da mesma forma, os conceitos média, mediana e moda podem ter servido de ancoradouros para as fórmulas apresentadas. As apropriações de novos conceitos possibilitam uma reestruturação da estrutura cognitiva, em um processo dinâmico (MOREIRA, 1997).

Vale ressaltar que os estudantes não utilizaram palavras de ligação ou palavras-chave entre os conceitos. Embora não sejam de uso obrigatório, as palavras-chave, segundo Moreira (1997) são úteis para estabelecer a relação entre dois conceitos. Isso não significa que o uso de palavras-chave torne um Mapa Conceitual autoexplicativo. Moreira (1997) esclarece que um Mapa Conceitual deve ser explicado por quem o confeccionou.

No segundo momento deste estudo, foi solicitado aos alunos que preenchessem um formulário do tipo Google Forms. Tendo como título, Mapas Conceituais no ensino de Matemática, e, como subtítulo, 


\section{revemop}

Medidas de Tendência Central: produção de Mapas Conceituais, uma proposta, o formulário era composto das seguintes questões, todas de preenchimento obrigatório, exceto a última.

1) Qual o seu nome?

2) Qual a sua turma?

3) O uso dos Mapas Conceituais, ajudam no estudo? ( ) Sim ( ) Não ( ) Talvez.

4) Qual a sua opinião sobre o uso dos Mapas Conceituais?

5) Ao estudarem Média Aritmética, Moda e Mediana, utilizando os Mapas Conceituais como ferramenta, você visualizou algum benefício? ( ) Sim ( ) Não ( ) Talvez.

6) Quais PONTOS POSITIVOS houve no estudo das Medidas de Tendência Central (Média, Moda e Mediana), a partir da confecção dos Mapas Conceituais? Houve PONTOS NEGATIVOS? Relate:

7) Quais os impactos que os Mapas Conceituais podem causar na SUA formação, levando em consideração que VOCÊ é um aluno (a) do $3^{\circ}$ ano do Ensino Médio e, está prestes a realizar o ENEM?

8) Você consegue enxergar OUTRAS UTILIZAÇÕES dos Mapas Conceituais? ( ) Sim ( ) Não ( ) Talvez.

9) Quais outras utilizações?

10) Se sua resposta for NÃO há outras utilizações, explique o porquê?

Todos os respondentes consideraram o uso de Mapas Conceituais como fundamentais para 0 processo de ensino e aprendizagem, além de ressaltarem a sua importância como técnica para estudar para o ENEM, justamente por ter que lidar com diversos conceitos que se relacionam.

\section{O uso dos Mapas Conceituais, ajudam no estudo?}
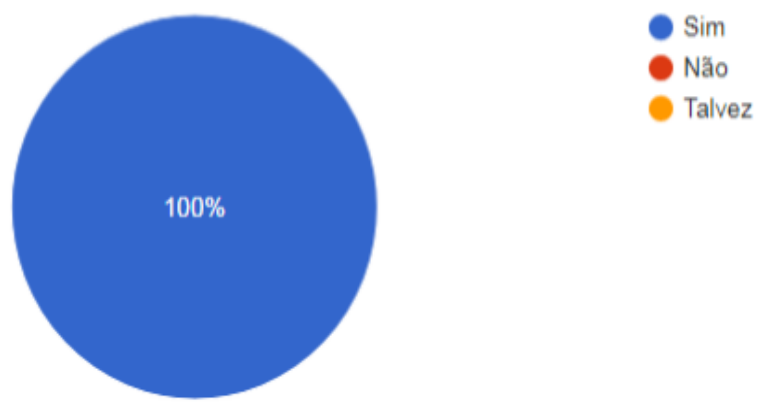

Figura 7: Respostas dos discentes - Importância dos Mapas (dados da pesquisa, 2020). 
Ainda nessa perspectiva, os estudantes afirmaram que os Mapas proporcionam maior rapidez no estudo de uma determinada matéria. A facilidade de organizar os conteúdos em esquemas, às vezes de forma resumida, auxilia na aprendizagem e na apropriação dos conceitos. Outro aspecto importante destacado pelos respondentes foi a representação figural que "fica guardada na mente". Um estudante ressaltou que, embora interessantes, os Mapas não podem ser utilizados em qualquer situação de aprendizagem.

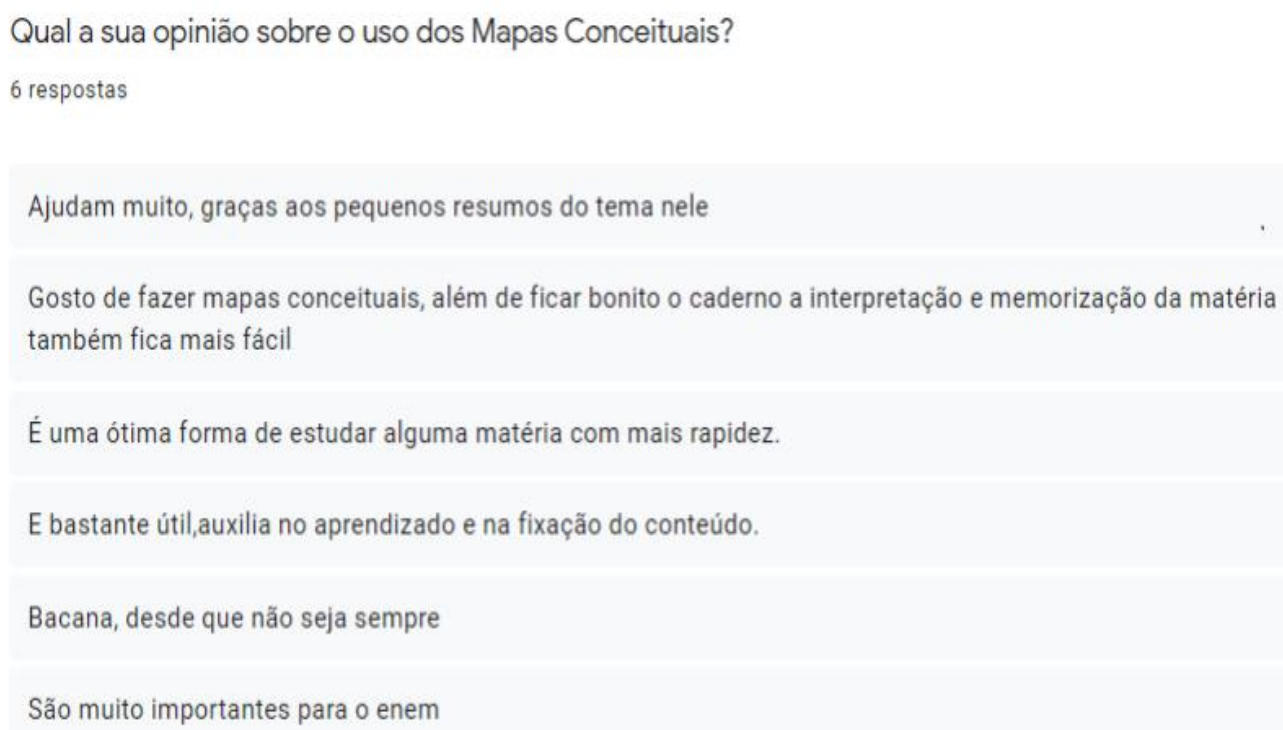

Figura 8: Opinião dos discentes sobre os Mapas - Google Forms (dados da pesquisa, 2020).

No tocante ao estudo das Medidas de Tendência Central com a utilização dos Mapas, metade dos alunos alegaram ver muitos benefícios a partir dessa ferramenta e, outra metade, alegou ter notado pelo menos algum benefício. Sobre o questionamento dos pontos negativos e positivos que verificaram no estudo desse segmento da estatística, os discentes abordaram que a utilização dos Mapas proporcionou uma melhor associação entre os termos, em que ficou compreendida a inserção de cada tópico dentro do termo geral, possibilitou melhor visualização mental, principalmente na hora dos exercícios.

Ao estudarem Média Aritmética, Moda e Mediana, utilizando os Mapas Conceituais como ferramenta, você visualizou algum beneficio?

6 respostas

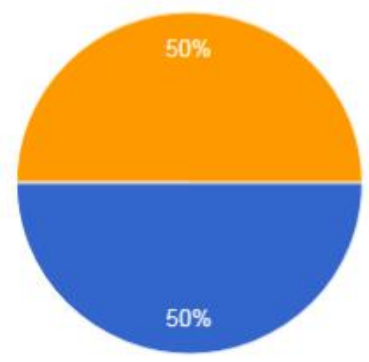

$$
\begin{aligned}
& \text { Sim } \\
& \text { Tão } \\
& \text { Talvez }
\end{aligned}
$$

Figura 9: Respostas dos discentes - Benefício dos Mapas no estudo de estatística (dados da pesquisa, 2020). 
Ainda sobre o questionamento anterior, alguns alunos apontaram a novidade em conhecer os Mapas Conceituais e, por isso, pensaram serem fortes aliados junto aos estudos preparatórios para 0 ENEM. Um dos alunos considerou que os Mapas da Matemática servem para organizar conteúdos mais teóricos. Outra estudante relevou que o uso dos Mapas tornou o estudo menos cansativo, pois quando há quantidade elevada de informação, os alunos acabam confundindo.

Ela relatou, ainda, que ajudou a organizar melhor o conteúdo e consequentemente, entender melhor a matéria. Por fim, outro aluno ressaltou que foi uma nova experiência pois havia parado de estudar e, com os Mapas, ele teve uma "visão ampla" dos conceitos (FIGURA 10). Essas considerações dos alunos foram encontradas nas respostas à pergunta: "Quais PONTOS POSITIVOS houve no estudo das Medidas de Tendência Central (Média, Moda e Mediana), a partir da confecção dos Mapas Conceituais? Houve PONTOS NEGATIVOS? Relate".

\author{
Positivos: consegui entender melhor a matéria sem ter muito cansaço, já que o texto muito grande pode \\ acabar confundindo um pouco e os resumos ajudam a não haver essa confusão \\ Por eu ter parado de estudar e voltar, da uma visão ampla dos conceitos da matéria gostei muito. \\ Acredito que para matemática, mapas conceituais não são muito práticos para mim, já que eu prefiro estudar \\ matemática fazendo exercícios, mas é bom para revisar matérias mais teóricas, além do mais eu já havia \\ feito os exercícios dessa matéria a muito tempo então não teve um impacto tão grande porque eu já faço \\ resumo em algumas matérias. \\ Um melhor entendimento do conteúdo e fixação \\ Me ajudou a organizar e compreender melhor a matéria \\ Descobrir uma nova área que eu não conhecia, e aprender materias do Enem
}

Figura 10: Respostas dos discentes - Pontos positivos no estudo de estatística (dados da pesquisa, 2020).

Sobre o questionamento dos impactos que os Mapas poderiam causar na formação desses estudantes que estão no $3^{\circ}$ ano do Ensino Médio e, às portas do vestibular, os estudantes entendem que com o elevado número de conteúdo para estudar, os Mapas são relevantes. Eles economizam tempo de estudo e auxiliam na fixação. Uma aluna associou os Mapas a outra importante ferramenta de estudo denominada Flashcards, pois são ótimos para revisar matérias de forma mais rápida, visto que muitos conteúdos são cobrados no ENEM, o que facilita a vida do aluno. Outras respostas estão na figura 11. 
Quais os impactos que os Mapas Conceituais podem causar na SUA formação, levando em consideração que VOCÊ é um aluno (a) do $3^{\circ}$ ano do Ensino Médio e, está prestes a realizar o ENEM?

6 respostas

Como são muitas matérias, os mapas podem ajudar na hora de gravar as matérias e estudar melhor

Facilidade para aprofundar na matéria pondendo usar como base para estudar para o enem

Flashcards, resumos e mapas conceituais são ótimos ora revisar matérias de forma mais rápida, visto que muitos conteúdos são cobrados no ENEM, o que facilita a vida do aluno.

Eles economizam tempo de estudo,e ajudam na fixação do conteúdo.

Os impactos são positivos, pois me ajudam mais do que a própria matéria

Muitos, pois eles são a base do Enem de matematica

Figura 11: Respostas dos discentes - Impactos dos Mapas na formação (dados da pesquisa, 2020).

Por fim, a pergunta relacionada às aplicações para os Mapas Conceituais, teve respostas interessantes. Os estudantes acreditam que eles podem ser utilizados em outros seguimentos da vida, como na organização de conteúdos da vida profissional, em disciplinas com muitos conteúdos teóricos, facilita no compartilhamento com amigos e colegas desde que sejam explicitadas as intenções na produção, por possuir valor pessoal.

\section{Você consegue enxergar OUTRAS UTILIZAÇÕES dos Mapas Conceituais?} 6 respostas

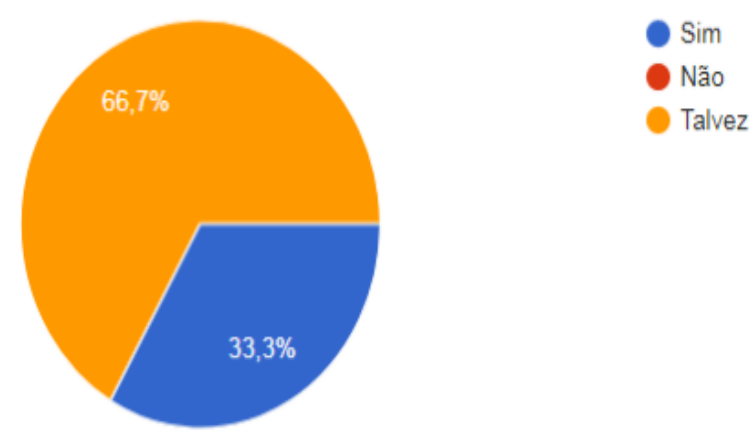

Figura 12: Respostas dos discentes - Outras utilizações dos Mapas (dados da pesquisa, 2020). 


\author{
Quais outras utilizações? \\ 6 respostas \\ Ajudar alguém que tenha mais dificuldade a entender melhor a matéria \\ Foco, estudo de estratégia e memorização \\ Em matérias de humanas, como história e geografia os mapas conceituais tem uma melhor utilização. \\ Facilita o compartilhamento do conteúdo com os amigos e colegas. \\ Compreender melhor \\ No Enem, em empregos talvez
}

Figura 13: Respostas dos discentes - Sobre as outras utilizações dos Mapas (dados da pesquisa, 2020).

No terceiro momento, foi proposta uma roda de conversa via Google Meet, cuja finalidade foi tecer algumas considerações acerca dos Mapas Conceituais e da experiência vivenciada no processo de construção. Participaram quatro estudantes, que apresentaram seus Mapas e o caminho utilizado na confecção de cada um. Reforçaram as ideias expostas no formulário do Google Forms e fizeram a recomendação para a aplicação desta atividade nas demais turmas do $3^{\circ}$ ano do Ensino Médio, dada a importância dessa ferramenta que possibilita melhorias no estudo e preparação para o ENEM.

\title{
7 Considerações
}

O presente estudo teve como objetivo geral evidenciar as percepções de estudantes do terceiro ano do Ensino Médio sobre o uso dos Mapas Conceituais na estruturação dos conceitos de média, moda e mediana para os estudos preparatórios para o ENEM, em um contexto de pandemia.

A partir dos dados coletados, os mesmos revelaram que os Mapas Conceituais, também enquanto MA, podem contribuir para a aprendizagem significativa dos estudantes, no sentido ausubeliano, ou seja, pode contribuir para que o estudante faça conexões entre o "novo" e o que estava em sua estrutura cognitiva, criando um todo coerente, pelo menos em sua perspectiva. A construção dos Mapas, por ser um processo individual, reflete a maneira como os estudantes compreenderam o que aprenderam. De certa forma, o Mapa apresenta um retrato de como os conceitos estão interligados na estrutura cognitiva dos estudantes. Isso ajuda, inclusive, para que o professor avalie sua prática e a aprendizagem dos estudantes.

Neste estudo, a partir das falas e respostas dos estudantes, pudemos desvelar algumas percepções acerca de como os Mapas Conceituais podem contribuir para a aprendizagem das medidas de tendência central, na preparação para o ENEM. Dentre essas percepções, podemos destacar que: os 
Mapas servem para estruturar um resumo da matéria; ajudam a memorizar o conteúdo; contribuem para a economia de tempo de estudo; possuem uma estrutura que ajuda aqueles que têm mais dificuldade para aprender os conteúdos; sua estrutura ajuda a organizar o estudo. Houve, também, estudantes que não perceberam muitas vantagens no uso de Mapas Conceituais. Um dos estudantes considerou os Mapas de pouca utilidade para ele, já que prefere estudar "fazendo exercícios".

De todo modo, os Mapas Conceituais tiveram boa aprovação por parte dos participantes. Ao que parece, seu uso pode trazer o estudante para o papel de protagonista de sua aprendizagem. Novos estudos poderão ser realizados, no sentido de mostrar possibilidades do uso de Mapas Conceituais no ensino de Matemática e com um grupo maior de estudantes.

O cenário de pandemia foi responsável por mudanças necessárias na forma de ensinar/aprender. Os reflexos dessas mudanças foram sentidos de várias formas. Se, por um lado, a adesão tem sido baixa, dadas as dificuldades de acesso de muitos estudantes, por outro, escancarou num pequeno espaço de tempo uma grande quantidade de plataformas digitais que, aliadas à criatividade e compromisso dos professores, constituíram-se como um novo modo de fazer pedagógico.

\section{Referências}

BRASIL. Ministério da Educação e do Desporto. Secretaria de Educação Média e Tecnológica. Parâmetro Curricular Nacional para o Ensino Médio - Matemática. Brasília: MEC/Semtec, 1999.

CIPRIANO, J. A.; ALMEIDA, L. C. C. S. EDUCAÇÃO EM TEMPOS DE PANDEMIA: Análises e implicações na saúde mental do professor e aluno. VII Congresso Nacional de Educação. Educação como (re)Existência: mudanças, conscientização e conhecimento. Anais. Maceió-AL. 11 p. 2020.

DIAS, É.; PINTO, F. C. F. A Educação e a Covid-19. Ensaio: aval.pol.públ.Educ. Rio de Janeiro, v. 28, n. 108, pág. 545-554, setembro de 2020. Disponível em: $<$ <ttp://www.scielo.br/scielo.php?script=sci_arttex t\&pid=S010440362020000300545\&lng=en\&nrm=iso>. Acesso em: 11 dez. 2020.

DIESEL, A.; BALDEZ, A. L. S.; MARTINS, S. N. Os princípios das metodologias ativas de ensino: uma abordagem teórica. Revista Thema, [S.I.], v. 14, n. 1, p. 268-288, fev. 2017. ISSN 2177-2894. Disponível em: <http://revistathema.ifsul.edu.br/index.php/thema/article/view/404>. Acesso em: 19 mar. 2020. doi:http://dx.doi.org/10.15536/thema.14.2017.268-288.404.

FRANCO, C. et al. Eficacia Escolar en Brasil: Investigando prácticas y politicas escolares moderadoras de desigualdades educacionales. In: CUETO, S. (Ed). Educación y brechas de equidade em America Latina. Chile: PREAL, p. 223-249. 2006.

GRILLO, M. C. et al. A gestão da aula universitária na PUCRS. Porto Alegre: EDIPUCRS, 2008. 170 p. Disponível em:<https://docplayer.com.br/10827148-A-gestao-da-aula-universitaria-napucrs.html>. Acesso em: 26 jun. 2020. 
JÚNIOR, V. C. A Utilização de Mapas Conceituais como Recurso Didático para a Construção e Inter-Relação de Conceitos. Revista Brasileira de Educação Médica. V. 37, n. 3, P. 441-447, mai. 2013. Disponível em: < https://www.scielo.br/pdf/rbem/v37n3/17.pdf>. Acesso em 25 jun. 2020.

MORAN, J. M. Mudando a educação com metodologias ativas. In: SOUZA, C. A; MORALES, O. E. T. (orgs.) Convergências Midiáticas, Educação e Cidadania: aproximações jovens. Vol. II. PG: Foca Foto-PROEX/UEPG, 2015, p. 15- 33.

MOREIRA, M. A. Mapas Conceituais e Aprendizagem Significativa (Concept maps and meaningful learning). Instituto de Física - UFRGS. 90501-970 Porto Alegre - RS, Brasil. P. 1-2, 1997.

Disponível

em:<https://https://docs.google.com/viewer?url=https\%3A\%2F\%2Fwww.if.ufrgs.br\%2F morei ra\%2Fmapasport.pdf >. Acesso em 24 set. 2020.

NOVAK, J. D. Aprender a criar e utilizar o conhecimento: mapas conceituais como ferramentas de facilitação nas escolas e empresas. Lisboa: Plátano, 2000.

NOVAK, J. D.; CAÑAS, A. J. A Teoria Subjacente aos Mapas Conceituais e como elaborá-los e usá-los. Práxis Educativa, Ponta Grossa, v.5, n.1, p. 9-29, jan.-jun. 2010. Disponível em: $<$ https://docs.google.c

om/viewer?url=https \%3A\%2F\%2Fdialnet.unirioja.es\%2Fdescarga\%2Farticulo\%2F3251296.pdf>. Acesso em: 24 set. 2020.

ONTORIA P. A.; GOMEZ, J. P.; MOLINA R. A. Potencializar a capacidade de aprender e pensar: o que mudar para aprender e como aprender para mudar. Tradução Fluvio Lulsisco. S. Paulo: Madras, 2004.

PIMENTEL, F. Metodologias Ativas. Educação Online, 2010. Disponível em:<http://fernandoscp imentel.blogspot.com.br/2010/08/metodologias-ativas.html>. Acesso em: 14 dez. 2020.

PRANDI, L. R. et al. As mazelas da Educação Pública no Brasil: do atraso à instrumentalização política do ensino. Educere - Revista da Educação, v. 15, n. 2, p. 203 217, jul./dez. 2015. Disponivel em:<https://revistas.unipar.br/index.php/educere/article/view/5620/3201>. Acesso em: 11 dez. 2020. 